\title{
BALANÇO HÍDRICO E CLASSIFICAÇÃO CLIMÁTICA NA BACIA DO RIO JAUQUARA, REGIÃO DE TRANSIÇÃO ENTRE O CERRADO E AMAZÔNIA BRASILEIRA
}

\author{
CASSETTARI, Gabriel Américo - cassettarig@gmail.com \\ Universidade do Estado de Mato Grosso/ UNEMAT \\ QUEIROZ, Tadeu Miranda de - tdmqueiroz@yahoo.com.br \\ Universidade do Estado de Mato Grosso/ UNEMAT
}

\begin{abstract}
RESUMO: A crescente demanda hídrica juntamente com a falta de planejamento e gestão de recursos hídricos traz impactos ambientais. Consequentemente, a produção agropecuária é afetada, por ser uma atividade econômica que depende de disponibilidade hídrica e está muito suscetível às condições meteorológicas e às oscilações climatológicas. O presente estudo objetivou estimar o balanço hídrico climatológico e fazer a classificação climática na Bacia Hidrográfica do Rio Jauquara, afluente do Paraguai Superior, por meio da interpolação de dados históricos de precipitação e temperatura das estações meteorológicas mais próximas à área de estudo. Através da interpolação dos dados obteve-se precipitação média anual de $1344,3 \mathrm{~mm}$ e temperatura média anual de $25,5^{\circ} \mathrm{C}$. O extrato do Balanço Hídrico Climatológico revelou $373,7 \mathrm{~mm}$ de déficit entre os meses de abril e outubro e excesso de $241,7 \mathrm{~mm}$ entre os novembro e março, sendo os meses críticos julho, agosto e setembro, com médias mensais de 63,9, 94,7 e 93,6 mm, respectivamente. O tipo climático foi representado pela fórmula C2 $\mathrm{WA}^{\prime} \mathrm{b}^{\prime} 4$, ou seja, clima Megatérmico com déficit hídrico moderado no inverno e evapotranspiração de 1476,2 $\mathrm{mm}$, ocorrendo $48 \%$ no verão. A interpolação dos dados climáticos permitiu estimar o balanço hídrico e realizar classificação climática, pois corrobora com a realidade da região estudada.
\end{abstract}

PALAVRAS-CHAVE: bacia hidrográfica; balanço hídrico; classificação climática; hidrologia; recursos hídricos.

\section{WATER BALANCE AND CLIMATE CLASSIFICATION IN THE JAUQUARA RIVER BASIN, REGION OF TRANSITION BETWEEN THE CERRADO AND BRAZILIAN AMAZON}

\begin{abstract}
The increasing hydric demand with lack of planning and resources management results in environmental impacts. Consequently, the agricultural production is affected for being an economical activity which depends on hydric disponibility and is very susceptible to the meteorological conditions and weather oscillations. The present study aimed to estimate the climatic water balance and to make the climate classification of Jauquara River Watershed, affluent of Paraguai river, by interpolation of precipitation and temperature historical data series, obtained from meteorological stations near by study area. Through data interpolation, it was obtained an average annual precipitation of $1344.3 \mathrm{~mm}$ and an average annual temperature of $25.5^{\circ} \mathrm{C}$. The extract of climatic water balance revealed deficit of $373.7 \mathrm{~mm}$ between April and October and excess of $241.7 \mathrm{~mm}$ between November and March, being July, August and September critical months with average of $63.9,94.7$ and $93.6 \mathrm{~mm}$ respectively. The climatic type was represented by index $\mathrm{C}^{2} \mathrm{wA}^{\prime} \mathrm{b}^{\prime} 4$, that indicates Megahermic climate with moderate water deficit in winter and evapotranspiration of $1476.2 \mathrm{~mm}$, occurring $48 \%$ in summer. The interpolation of climatic data allowed to estimate the water balance and climatic classification since ir corroborates with the studied region reality
\end{abstract}

KEYWORDS: climatic classification; hydrology; hydrographic basin; water balance; water resources. 


\section{INTRODUÇÃO}

Em muitas áreas do planeta Terra houve aumento no interesse em aquisição de águas de regiões terceiras, por conta da escassez hídrica e consequentemente a ocorrência de problemas ambientais e socioeconômicos (BURT,1999). Essas ocorrências ilustram a necessidade de pesquisas direcionadas para o conhecimento do regime hídrico de uma região, especialmente em escala de bacia hidrográfica, como ferramenta para planejamento, uso e conservação dos recursos hídricos. A água ajudou a escrever a história: o homem ocupou territórios, cresceu e se desenvolveu explorando a água como recurso natural inesgotável. No entanto, o crescimento vertiginoso da população mundial tem diminuído a disponibilidade de água em muitos locais, seja pelo uso exagerado, pela contaminação dos mananciais, ou mesmo pelo aumento da demanda, entre outros fatores, o que tem gerando conflitos e situações de miséria.

Diante de situações de demanda maior do que a oferta a água passou a ser vista como recurso e não mais com um bem natural, gratuito e infinito (BACCI \& PATACA, 2008). No Brasil a Lei das Águas, institui a Política Nacional de Recursos Hídricos e partir dela inicia-se a conscientização pelo uso racional da água sob a ótica do desenvolvimento sustentável. Surgem também os comitês de bacia que passam a gerenciar a disponibilidade hídrica democraticamente, observando a oferta, a demanda, as prioridades e os possíveis conflitos entre o abastecimento urbano, o industrial e o agropecuário, sendo este último visto como vilão devido ao grande volume de água demandado para a produção.

A produção agropecuária é uma atividade econômica muito dependente das condições meteorológicas, principalmente quanto à disponibilidade hídrica (CECÍLIO et al., 2012) e climáticas, por sua influência sobre o desenvolvimento dos seres vivos no ambiente ao qual estão inseridos (MEDEIROS et al., 2013). Há de se ressaltar que cada cultura se comporta de forma diferente e possui demanda distinta para seu crescimento e desenvolvimento em relação aos fatores climáticos e ambientais (RADIN \& MATZENAUER, 2016). Em contrapartida o setor agropecuário tem empregado tecnologias buscando maximizar a produtividade, empregando engenharia genética para criação de novas espécies com maior eficiência no uso da água, além de novas técnicas de plantio e manejo.

Muitos projetos de campo acabam mal sucedidos devido a sua vulnerabilidade frente às condições meteorológicas e ineficiência no planejamento e controle de distribuição de água (FREITAS et al., 2010). Corrobora a isso a falta de investimento em estruturas que poderiam potencializar o melhor aproveitamento do recurso hídrico e o uso indiscriminado ainda praticado por usuários que permanecem à margem da Lei.

Desta forma, os estudos hidrológicos se fazem necessários, pois possibilitam a obtenção de informações importantes para o manejo e gestão das bacias e entendimento de fenômenos físicos como infiltração do solo e dinâmica do escoamento superficial. Além disso, novas informações de uma bacia ou região hidrográfica podem nortear políticas públicas e orientar ações de mediação de conflitos em regiões de escassez hídrica, colaborando com o conhecimento mais detalhado dos recursos hídricos de um determinado lugar. 
Um dos métodos clássicos para a contabilização de água do solo é o Balanço Hídrico Climatológico (BHC) proposto por Thorntwaite e Mather (1955). A partir do princípio da conservação de energia, este método contabiliza a disponibilidade hídrica utilizando as variáveis precipitação e temperatura como entradas e evapotranspiração real, excedente ou déficit como saídas (AQUINO, 2013).

Há de se considerar as dificuldades em se estimar a evapotranspiração que acarretam a carência de informações, devido ao alto custo de equipamentos de medição direta. Desta forma é estimada a evapotranspiração de referência (Eto), através de técnicas e modelos matemáticos indiretos que demandam menor custo e tempo (SOBRINHO et al., 2011).

Os dados gerados a partir do BHC vêm sendo aplicados em diversas áreas do conhecimento, como em estudos de classificação climática, caracterização hidrológica, planejamento de práticas agrícolas. Sendo assim, tocante à Agrometeorologia, é uma ferramenta de grande utilidade em vista de melhor gestão dos recursos hídricos (DOURADO-NETO et al., 2010).

Por meio da obtenção de dados climáticos é empregado em ensaios de curto e longo prazo, utilizando séries temporais (ZHANG, 2002).

O método clássico de Thorntwaite e Mather (1955) pode ser adaptado para situações distintas, com séries temporais de curto e longo prazo (ZHANG, 2002). Autores como Eaton (1995) e Swanson (1996), mostraram que a partir da inserção de alguns elementos no modelo é possível trabalhar o BHC com escalas temporais menores, enquanto Van Der Molen (1986), Rhuston, Eiler e Carter (2006) aperfeiçoaram o método utilizando escalas diárias (DOURADONETO, 2010).

Este método é comumente utilizado de forma pontual para estações com disponibilidade de dados. Contudo, em áreas nas quais não há disponibilidade destes se faz necessário o emprego de métodos de interpolação espacial (CECÍliO et al., 2012).

A medida que os estudos sobre climatologia avançam, fica cada vez mais evidente a abrangência das diferentes classificações climáticas em inúmeras aplicações, como mapeamento de áreas, classificação de rios, modelos de comportamento atmosférico, avanço dos impactos atribuídos ao efeito estufa, evolução de endemias entre outros (NOBREGA, 2010).

Sendo o clima dependente de fatores ambientais (vegetação, precipitação, solo, temperatura, umidade do ar, evapotranspiração) e fatores antrópicos, não se pode afirmar que os diversos sistemas de classificação climática (SCC) - que buscam simplificar a compreensão do clima através da entrada de dados discretos - sejam perfeitos e não apresentem falhas.

Destacam-se entre os principais SCC o modelo de Köppen e Thorntwaite. O primeiro, busca classificar o clima com base na temperatura enquanto o segundo, propõe a classificação utilizando-se das informações de precipitação e temperatura para então estimar o clima através da evapotranspiração potencial, índice de umidade e aridez (AYOADE, 1996). Pode-se assim afirmar que no SCC de Thorntwaie o BHC é indispensável.

A importância desta pesquisa deve-se ao fato de que a área estudada possui carência de informações ambientais, além de ser uma região bastante 
afetada nas últimas décadas pelas atividades antrópicas em decorrência da agricultura mecanizada e das populações que vivem na região (CASARIN, 2008). Ribeiro et al. (2017) analisaram as pressões antrópicas na Bacia hidrográfica Paraguai-Jauquara entre os anos de 1993 e 2014 e verificaram nesse período aumento da área ocupada pela agricultura de 0,95\% para 1,39\% e aumento das pastagens de $22,09 \%$ para $34,78 \%$. Tais aumentos implicaram na redução das massas d'água detectáveis de $0,26 \%$ para $0 \%$, e redução da vegetação natural de $76,4 \%$ para $63,77 \%$.

Este trabalho é parte dos resultados de um projeto de pesquisa que visa estudar os recursos hídricos na Bacia Hidrográfica do Rio Jauquara (BHRJ), importante afluente do Rio Paraguai Superior. Em visitas de campo mensais desde fevereiro de 2016, percorrendo as duas margens do referido rio, da nascente à foz, foi possível observar ao longo das rotas, diversas obras de acumulação de água (barragens, cacimbas, bolsões) principalmente nas propriedades cuja atividade é a pecuária de corte extensiva. Observaram-se também relatos da população dando conta da dificuldade de convivência com a seca e acesso à água para atividades cotidianas. No período chuvoso nota-se intenso escoamento superficial, com formação de trombas d'água, conforme testemunhos locais e observação visual. Já no período de estiagem observam-se diversos tributários secos. Tais fatos motivaram a busca de informações mais detalhadas sobre o regime hídrico local.

A disponibilidade hídrica de uma região pode ser explicitada e explicada pelo balanço hídrico considerando uma série de dados climatológicos e a classificação climática, utilizando-se desses mesmos dados, permite conhecer o tipo climático do local além oportunizar comparações com regiões semelhantes, que se torna uma ferramenta de gestão de recursos hídricos importante, pois permite a construção de cenários futuros e o planejamento de ações de intervenção. E quando isso é feito para uma bacia hidrográfica os resultados funcionam como uma lente de aumento que permite visualizar com mais detalhe o que ocorre naquele local, diferentemente do que ocorre quando se utiliza de uma classificação mais ampla, para o território nacional ou estadual, as quais perdem a sensibilidade dificultando o conhecimento e observação de microclimas regionais.

A literatura científica oferta diversas metodologias de classificação climática. A primeira delas, a de Wilhelm Köppen publicada no ano de 1900 propôs uma classificação do clima baseada em grandes associações vegetais. 0 mesmo autor, 18 anos mais tarde, aperfeiçoou sua classificação considerando os limites térmicos, pluviométricos e características das estações. Já Thornthwaite em 1948 acrescentou a evapotranspiração com elemento de classificação do clima. Mais tarde, em 1955, Thornthwaite e Mather utilizaram índices climáticos definidos com base no Balanço Hídrico Climatológico. Essa última é considerada a metodologia mais clássica de regionalização climática e a mais refinada para aplicações agrícolas, pois considera a planta como um meio físico pelo qual é possível transportar água do solo para atmosfera relacionando às necessidades hídricas das plantas ao balanço hídrico, conforme o tipo de clima (SILVA et al., 2014).

Neste contexto e condições, o presente estudo objetivou estimar o balanço hídrico climatológico na BHRJ, por meio da interpolação de dados históricos de precipitação e temperatura das estações meteorológicas mais 
próximas à área de estudo e fazer a classificação climática proposta por Thorntwaite e Matther (1955).

Este trabalho ganha relevância uma vez que a região de estudo é sustentada pela agropecuária, sendo a pecuária de corte extensiva a atividade predominante, além do cultivo de cana de açúcar para o setor sucroalcoleiro e agricultura familiar diversificada. Deste modo, o conhecimento climático regional pode nortear investimentos e adaptações no setor produtivo, constituindo novos postos de trabalho com geração de emprego e renda e, por conseguinte 0 desenvolvimento regional.

\section{METODOLOGIA}

\section{ÁREA DE ESTUDO}

Este trabalho foi desenvolvido no Laboratório de Qualidade de Água (LaQuA) da Universidade do Estado de Mato Grosso (UNEMAT), no Campus de Barra do Bugres.

A área de estudo é a região de transição Pantanal-Cerrado-Amazônia, onde a vegetação é tipicamente savânica com poucas formações florestais, características de vegetação do cerrado e pré-amazonicas (MARACAHIPES, 2011) e áreas sujeitas a inundação (campos inundáveis) feições características do pantanal (ADAMI, 2008).

A BHRJ localiza-se entre os munícipios de Barra do Bugres, Porto Estrela, Nossa Senhora do Livramento e Rosário Oeste. Está situado entre as coordenadas $57^{\circ} 15^{\prime} \mathrm{O}$ e $56^{\circ} 45^{\prime} \mathrm{O}$ longitude, $15^{\circ} \mathrm{S}$ e $15^{\circ} 50^{\prime} \mathrm{S}$ latitude; Sua cabeceira localiza-se próxima à rodovia MT-160, numa região denominada "Coqueiro".

A BHRJ configura-se como importante aglomerado de tributários que compõem o conjunto de Bacias Paraguai/Jauquara (BHPJ), que conta com mais oito bacias e se expande pela margem esquerda do Rio Paraguai (CASARIN, 2008). A paisagem típica é composta por elevações e baixadas que "fazem parte da Província Serrana, um corredor de serras com cerca de $400 \mathrm{~km}$ de comprimento por $40 \mathrm{~km}$ de largura, o qual conecta o Cerrado à transição do bioma Amazônico e ao Pantanal" (VALADÃO, 2012).

A maior parte da BHRJ é composta por áreas de preservação nas formações serranas. Nas áreas planas entre os filetes de serras, acomodam-se populações remanescentes de quilombos e assentados do INCRA os quais praticam agricultura de subsistência. As porções de terras planas mais extensas sustentam, predominantemente, atividades de pecuária de corte extensiva. Nas proximidades da foz do rio encontram-se empreendimentos de monocultura de cana de açúcar e próximo à nascente está se iniciando um processo de substituição de pastagens por soja e outras culturas anuais em rotação.

A BHRJ possui área de $1408 \mathrm{~km}^{2}$ com curso d'água principal medindo $110 \mathrm{~km}$ e tempo de concentração de 1009 min. A rede de drenagem é bem ramificada de formato dendrítico e de $5^{a}$ ordem. A altitude na bacia varia entre 150 e $920 \mathrm{~m}$, com predomínio de relevo suave ondulado e ondulado. As atividades econômicas predominantes são a pecuária de corte extensiva e a monocultura da cana-de-açúcar para o setor sucroalcoleiro, mas constatam-se 
também atividades da agricultura familiar praticada em Comunidades Remanescentes de Quilombos e Assentamentos da Reforma Agrária (CASSETTARI \& QUEIROZ, 2019). A vegetação predominante é composta por matas e variações de cerrados (PESSOA et al., 2014).

Em estudo realizado por Ferreira (2015) verificou-se, em relação ao uso do solo na BHRJ, que predominam as áreas de vegetação nativa com $65,87 \%$ da área total, seguido por pastagens com 26,88\%, Agricultura com 7,14\% e massas de água com $0,10 \%$.

Na Figura 1 apresentam-se aspectos da paisagem e uso do solo da BHRJ, onde se observa a agricultura (A), pecuária (b), cachoeira (c), cânion (d), a vegetação nativa no médio Rio Jauquara (e) e estrutura habitacional em Comunidade Remanescente de Quilombo ( $f$ ).

A

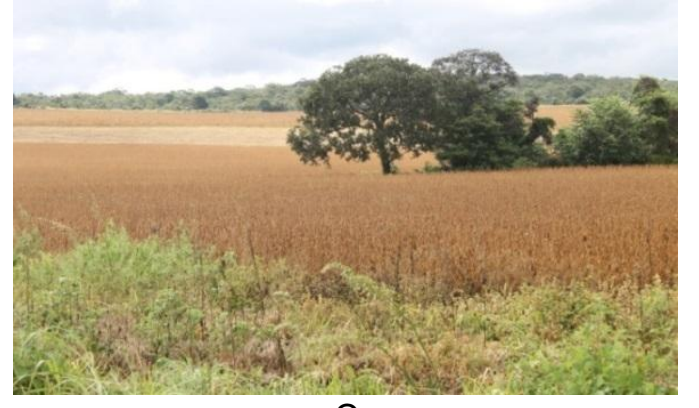

C

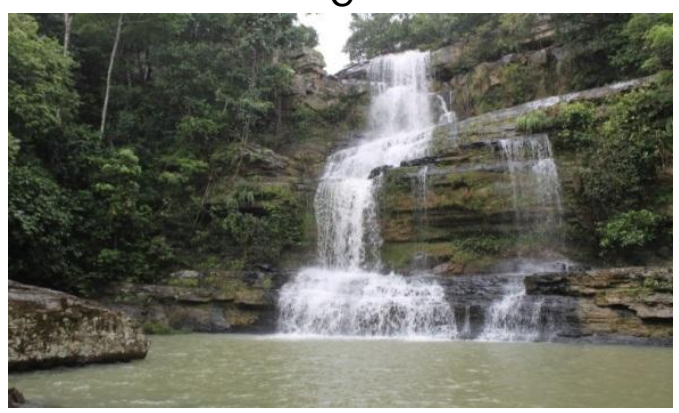

E

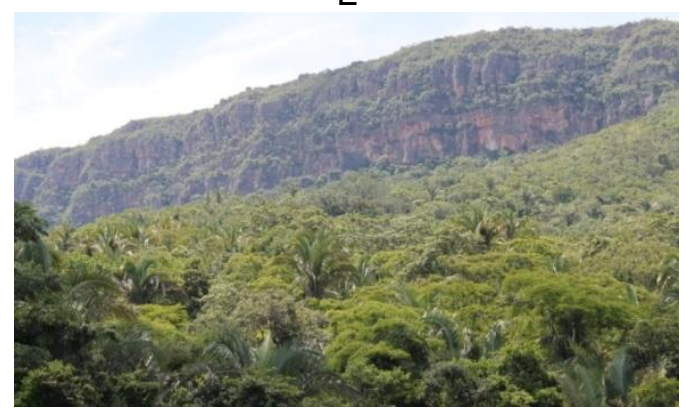

B

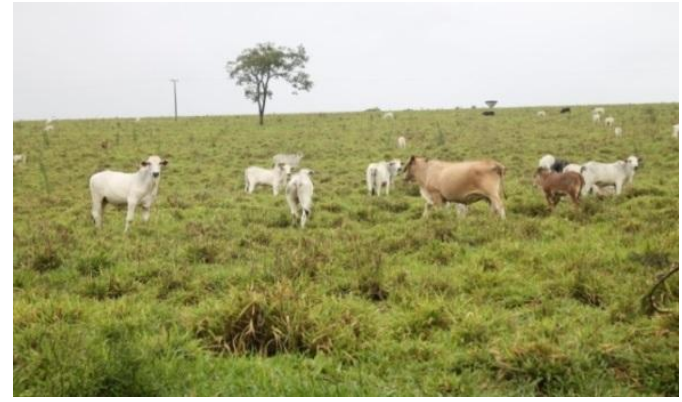

D

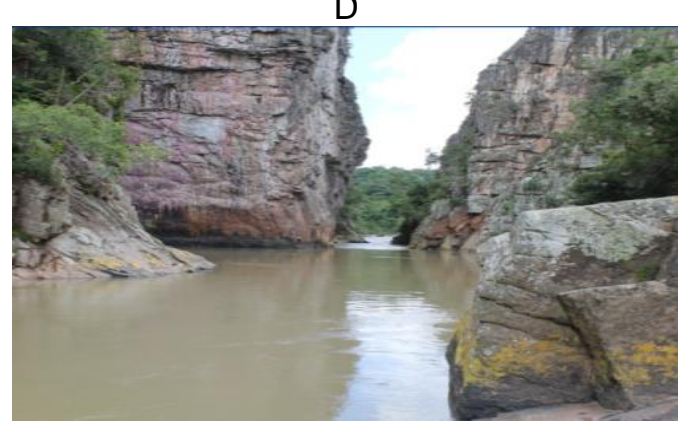

$\mathrm{F}$

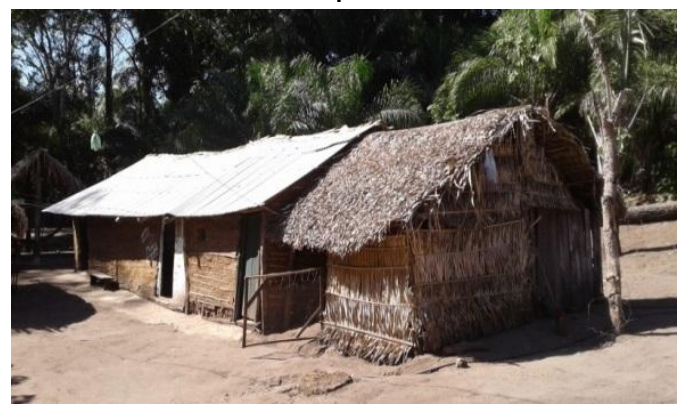

Figura 1 - Aspectos da paisagem e uso do solo na BHRJ.

\section{INTERPOLAÇÃO DE DADOS CLIMÁTICOS}

A região de estudo não possui estações meteorológicas, portanto foi necessário realizar uma estimativa das médias mensais das variáveis temperatura e precipitação, através de preenchimento de falhas por 
Interpolação pelo Inverso da Distância (IID). Este método consiste em estimar uma variável quantitativa em uma determinada localidade (ponto coordenado) que não possui este dado a partir de dados obtidos de localidades (estações) mais próximas, pela ponderação proporcional ao inverso da distância da localidade estimada (KURTZMAN \& KADMON, 1999).

A consistência do método se dá pela influência da distância exercida pelas estações que contém as bases de dados. Sendo assim, quanto mais próximas estiverem as estações do ponto interpolado, mais preciso será o resultado obtido.

É vasta a utilização desta metodologia na literatura, sendo seu emprego submetido a diferentes testes estatísticos de validação, os quais têm evidenciado acurácia e precisão, como nos trabalhos de Bier e Ferraz (2017); Apaydin (2004), utilizando a interpolação para estimar temperatura e precipitação.

A IID foi realizada utilizando os dados das estações meteorológicas mais próximas à BHRJ (Cáceres - ao sul do CG, Cuiabá - em Latitude próxima e Diamantino - ao norte do CG), conforme esquema apresentado na Figura 2. Ressalta-se que outras estações com dados de precipitação e temperatura disponíveis estavam a distâncias superiores a 200 km do CG em linha reta, por isso não foram utilizadas.

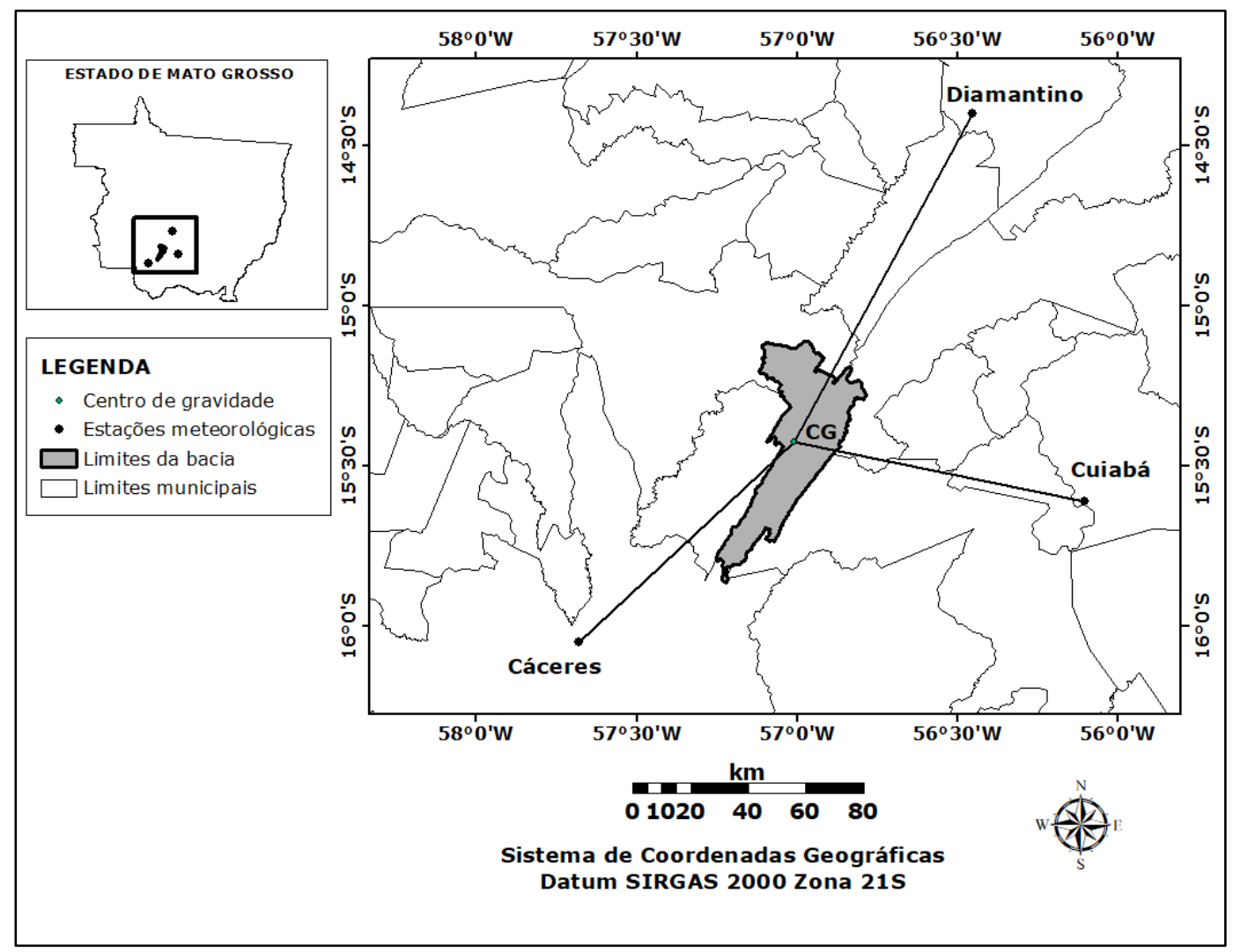

Figura 2 - Localização geográfica da BHRJ e estações meteorológicas mais próximas. 
A espacialização dos pontos, cálculo da distância linear e determinação do centro de gravidade da bacia foram feitos em um software de geoprocessamento, utilizando o sistema de coordenadas projetadas SIRGAS 2000 UTM Zona 21s.

As bases de dados utilizadas foram as séries históricas de precipitação e temperatura do Instituto Nacional de Meteorologia (BDMEP).

Como todas as séries levantadas apresentaram variações no horizonte de tempo e lacunas em alguns meses, e foge ao foco do presente trabalho avaliar as variações de precipitação e temperatura ao longo do tempo, foram desconsiderados os anos com dados faltantes utilizando as séries apresentadas na Tabela 1.

Tabela 1 - Localização geográfica, distância ao centro de gravidade e intervalo de dados levantados das estações meteorológicas.

\begin{tabular}{|c|c|c|c|c|}
\hline \multirow{2}{*}{ Estação } & Coordenad & jeográficas & \multirow{2}{*}{$\begin{array}{l}\text { Distância em } \\
\text { relação ao } \\
\text { centro de } \\
\text { gravidade } \\
(\mathbf{k m})\end{array}$} & \multirow{2}{*}{ Intervalo de dados } \\
\hline & $\begin{array}{l}\text { Latitude } \\
\text { (Sul) }\end{array}$ & $\begin{array}{l}\text { Longitude } \\
\text { (Oeste) }\end{array}$ & & \\
\hline Cáceres & $16^{\circ} 03^{\prime} 00^{\prime \prime}$ & $57^{\circ} 40^{\prime} 48^{\prime \prime}$ & 99,96 & $\begin{array}{c}\text { (1961-1965); (1971- } \\
\text { 1990); 1995; (1998- } \\
\text { 2013). }\end{array}$ \\
\hline Cuiabá & $15^{\circ} 36^{\prime} 36^{\prime \prime}$ & $56^{\circ} 06^{\prime} 00^{\prime \prime}$ & 99,48 & $\begin{array}{c}\text { (1961-1989); 1993; 1995; } \\
(1998-2017) .\end{array}$ \\
\hline Diamantino & $14^{\circ} 24^{\prime} 00^{\prime \prime}$ & $56^{\circ} 27^{\prime} 00^{\prime \prime}$ & 128,2 & $\begin{array}{l}\text { (1961-1965); (1969- } \\
\text { 1995); (1998-2017). }\end{array}$ \\
\hline
\end{tabular}

O cálculo do método IID foi realizado por meio da equação:

$$
D_{x}=\frac{\sum_{i=1}^{3}\left(D_{i} / d_{i}\right)}{\sum_{i=1}^{3}\left(1 / d_{i}\right)}
$$

Em que:

$D_{x}$ é a variável mensal interpolada da estação com dados faltantes;

$D_{i}$ é o dado mensal ocorrido na estação vizinha de ordem i;

$d_{i}$ é a distância entre a estação com dados faltantes e a estação vizinha de ordem i.

\section{BALANÇO HÍDRICO CLIMATOLÓGICO E CLASSIFICAÇÃO CLIMÁTICA}

Para o cálculo do Balanço Hídrico Climatológico de Thorntwaite e Mather (1955) foi utilizada a metodologia descrita em Pereira, Angelocci e Sentelhas (2002), utilizando $100 \mathrm{~mm}$ para Capacidade de Água Disponível (CAD), possibilitando estimar excedente (EXC), deficit (DEF), evapotranspiração 
potencial (ETP) e evapotranspiração real (ETR). De posse das informações obtidas do BHC, foram calculados os Índices Hídrico (Ih), Aridez (Ia), e Umidade (Iu) denotados por:

$$
\begin{aligned}
& I h=\frac{E X C}{E T P} 100(3) \\
& I a=\frac{D E F}{E T P} 100(4) \\
& I u=I h-0,6 I a(5)
\end{aligned}
$$

A classificação climática foi realizada por meio das chaves de classificação de Thorntwaite e Matther (1948) citada por Ometto (1981), a qual se baseia na variação dos três índices supracitados, na ETP anual e concentração da ETP no verão em porcentagem. Embora essa metodologia de classificação climática seja relativamente antiga está sendo largamente utilizada na atualidade como demonstram os trabalhos de Freitas et al. (2011), Aquino e Oliveira (2013), Matos et al. (2015), entre outros. A motivação para trabalhos de classificação climática na atualidade tem respaldo nas intensas discussões sobre mudanças climáticas em todo o mundo.

Dentre as classificações climáticas consolidadas internacionalmente destacam-se as classificações de Koppen proposta em 1900 e aperfeiçoada por Geiger entre 1918 e 1936 e a de Thortwaite e Matther (1948). Neste estudo optou-se pela segunda em virtude desta metodologia ter estreita relação com o regime hídrico e aplicações na agricultura.

Também foi utilizada a metodologia de Thorntwaite (1948) para classificação de meses secos (aridity) e úmidos (humidity) com base em precipitação (P) e evapotranspiração (ETP) mensal, fazendo a razão entre a diferença P - ETP e ETP. Nessa mesma linha Miranda e Santos (2008) apresentaram resultado apenas para a razão entre $P$ e ETP gerando um índice cujo valor, quando maior que 1,00 indica que o mês é chuvoso e quando menor que 1,00 indica mês seco. Na prática esse resultado leva à mesma interpretação dos resultados obtidos pela metodologia de Thorntwaite (1948), mas acrescenta a possibilidade de se mensurar quão mais seco ou mais chuvoso é cada mês e ainda, a média dos valores de cada estação permite comparações entre regiões diferentes.

\section{RESULTADOS E DISCUSSÕES}

Com a obtenção das médias pluviométricas e de temperatura mensais, foi possível o emprego do método de Thorntwaite e Mather (1955) para estimativa do BHC e confrontar o que foi obtido com base na literatura, em trabalhos semelhantes nos municípios onde estão situadas as estações meteorológicas utilizadas para a interpolação.

O resultado do BHC para Precipitação, Temperatura, Evapotranspiração Potencial e Real são apresentados na Figura 3. 


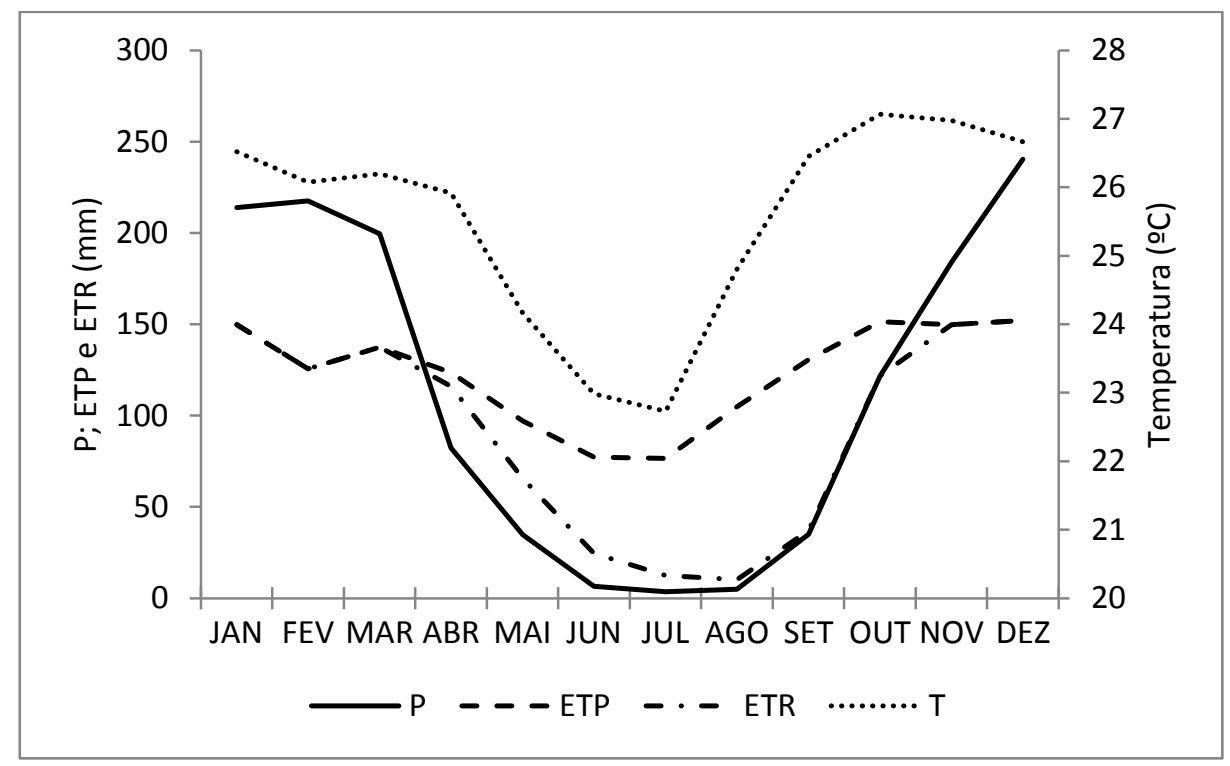

Figura 3 - Resultado do Balanço Hídrico Climatológico para o Centro de Gravidade da BHRJ: Precipitação média (P), Evapotranspiração Potencial (ETP), Evapotranspiração Real (ETR) e Temperatura Média (T).

A precipitação total média anual acumulou 1344,3 mm contra 1476,2 $\mathrm{mm}$ de evapotranspiração potencial, evidenciando uma demanda hídrica potencial estimada de $8,9 \%$ maior que a precipitação. Isso acontece porque a água armazenada e disponível no solo não é suficiente para prover todo o potencial evapotranspirométrico limitando a evapotranspiração real com efeito direto no desenvolvimento dos organismos vegetais.

Neste cenário fica evidente, que a irrigação, no período de estiagem, caracteriza-se como uma ferramenta fundamental para garantir a produção com qualidade na entressafra, significando também possibilidade de diversificação da produção e aumento da produção de alimentos, o que pode ser bastante significativo socialmente para as comunidades renascentes de quilombos e assentados do INCRA, que vivem no local, além de outros agricultores familiares e ribeirinhos.

Pela Figura 3 pode-se observar que as maiores médias pluviométricas ocorrem entre dezembro e março (período úmido), com médias superiores à $200 \mathrm{~mm}$. Os meses que apresentam menor pluviosidade são os meses entre maio e setembro (período seco), com médias inferiores à $40 \mathrm{~mm}$. Desse modo, verifica-se a ocorrência de dois períodos diferentes em relação à entrada de água (chuva): um com alta e outro com baixa pluviosidade. Tal situação é típica da região Centro-Oeste do Brasil como demonstra o trabalho de Parreira et al. (2019) para a região de Rio Verde-GO, o qual obteve resultado semelhante.

Por esse resultado nota-se a severidade hídrica no período seco, de modo que a manutenção dos rios e córregos da bacia e o ciclo hidrológico se tornam mais lentos, com menor entrada de água no sistema. Mota et al. (2013) encontraram valores semelhantes para a pluviosidade ao estudar o BHC na região de Sinop, estado de Mato Grosso, corroborando com essa pesquisa. 
A evapotranspiração das plantas depende da quantidade de água armazenada no solo (ROSSATO et al., 2004). Neste sentido observa-se pela Figura 3 que as curvas de evapotranspiração potencial e real sofrem um declínio na estação seca, a partir do mês de abril, se estendendo até o mês de setembro, indicando possível redução da evapotranspiração em função do déficit de água no solo, o que certamente compromete o pleno desenvolvimento das culturas.

Na Figura 4 apresenta-se o resultado do BHC para os períodos de déficit, excesso, reposição e retirada.

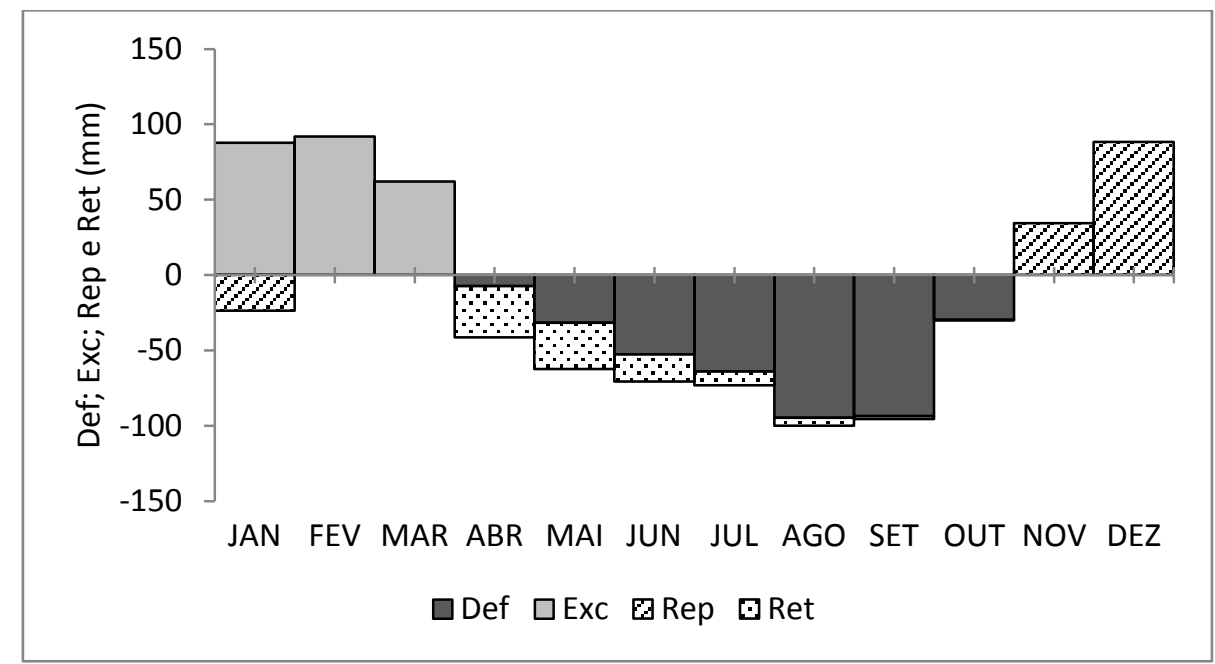

Figura 4 - Resultado do Balanço Hídrico Climatológico para o Centro de Gravidade da BHRJ: Déficit (Def), Excesso (Exc), Reposição (Rep) e Retirada (Ret).

A partir da Figura 4, é possível observar que há três situações distintas. Entre os meses de janeiro e março há excedente hídrico ( $P>E T P)$, com pico no mês de fevereiro, o qual apresentou armazenamento em excesso de 91,96 mm. Os meses que mais apresentaram déficit (ETP>ETR) foram julho, agosto e setembro (63,9, 94,7 e 93,6 mm, respectivamente). Nos meses de novembro e dezembro o $\mathrm{BHC}$ foi 0 , o que indica que não há nem excedente nem déficit, ilustrando a reposição $(P-E T P \geq 0)$ de água no perfil do solo (período que se estende até janeiro), fenômeno comum também observado no trabalho de Miranda e Santos (2008) para a microrregião de Duas Barras/RJ no mês de outubro.

As situações de excedente, déficit e reposição são características do local e tem origem na combinação do armazenamento de água no perfil do solo, na distribuição de precipitação, na evapotranspiração potencial e real.

O regime hídrico depende da configuração local, fatores climáticos e fisiográficos (GUTIÉRREZ, 2013). Souza (2013) ressalta que os ventos e o relevo contribuem para diferenças substanciais de temperatura, precipitação e evapotranspiração para regiões com latitudes próximas. No norte do estado de Mato Grosso há maior incidência de ventos, pois se constitui de regiões serranas com altitude mais elevada em relação à Baixada Cuiabana, a qual contém municípios com altitudes próximas a $180 \mathrm{~m}$, semelhantes à área de estudo. 
Os ventos são transportadores de umidade ("rios voadores") e por isso contribuem com o regime de precipitação de um determinado local (REBOITA et al., 2010). O vento também é fator influenciador da evapotranspiração sendo que a evapotranspiração será tanto maior, quanto maior for a duração e intensidade do vento (LEMOS FILHO et al., 2010). Já o relevo influencia na ocorrência e intensidade de precipitação de uma região conforme sua orientação, forma, declividade e altitude. Portanto, funciona como um controle geográfico atuando na diversificação dos tipos de clima. Variações de altitude influenciam na distribuição das chuvas e de temperatura de uma determinada região como demonstrado por Oliveira e Galvani (2015) para o perfil longitudinal Parati (RJ) e Campos do Jordão (SP).

Na Tabela 2 apresentam-se os resultados calculados para a classificação climática, o enquadramento de cada índice, a simbologia e interpretação.

Tabela 2 - Índices de Umidade $\left(I_{u}\right)$, Aridez $\left(I_{a}\right)$, Evapotranspiração Potencial Total $\left(E T P_{\text {anual }}\right)$ e Evapotranspiração no Verão (ETP verão) e classificação climática para a BHRJ.

\begin{tabular}{cccc}
\hline Índice & Valor & Simbologia & Interpretação \\
\hline $\mathrm{I}_{\mathrm{u}}$ & $1,19 \%$ & $\mathrm{C}_{2}$ & Sub úmido \\
$\mathrm{I}_{\mathrm{a}}$ & $25,31 \%$ & $\mathrm{~W}$ & Déficit hídrico moderado no inverno \\
ETP $_{\text {anual }}$ & $1.476, \mathrm{~mm}$ & $\mathrm{~A}^{\prime}$ & Megatérmico \\
ETP $_{\text {verão }}$ & $48,41 \%$ & $\mathrm{~b}_{4}^{\prime}$ & ETP $_{\text {verão entre } 48-51,9 \%}$ \\
\hline
\end{tabular}

Através da primeira chave, baseada no índice de umidade, obteve-se clima do tipo sub-úmido. Analisando a segunda chave, baseada nos índices de aridez e umidade, caracteriza-se a BHRJ com moderada deficiência hídrica no inverno. Por meio da terceira chave, com base na evapotranspiração anual, classifica-se o clima da região como megatérmico. Por fim, a quarta chave, que se baseia na concentração da evapotranspiração no verão, obteve-se o subtipo b'4. O índice hídrico (Ih) obtido $(16,37 \%)$ contribuiu para o cálculo do índice de umidade (Iu), entretanto não há uma interpretação direta para este índice conforme as chaves de classificação. Portanto, a classificação climática de Thorntwaite e Mather (1955) para a BHRJ indica clima C2WA'b'4, ou seja, região com déficit hídrico moderado no inverno e evapotranspiração de 1476,2 mm, ocorrendo $48 \%$ no verão. Segundo Ayoade (1996) a classificação de Thorntwaite (1948) foi bastante criticada entre estudiosos, sobretudo pelos índices de umidade e aridez muitas vezes considerados inconsistentes em determinadas áreas do planeta. Contudo a classificação obtida por meio destes índices para a região estudada traz um respaldo positivo, pois de fato observase a ocorrência de déficit hídrico no inverno e excedente no verão.

Em comparação com Souza et al. (2013), que realizaram o BHC e SCC para 13 estações meteorológicas de municípios distintos no estado de Mato Grosso, o resultado obtido para a BHRJ se assemelha às estações de Aragarças, Nova Xavantina e Rondonópolis, localidades com altitude superior à região de estudo, o que evidencia ainda mais que um SCC não está limitado apenas à um, mas sim uma combinação de fatores de influência, como o regime de chuvas (intensidade e frequência), ventos, insolação, temperatura do ar, cobertura do solo, entre outros. Aragarças-GO está $680 \mathrm{~km}$ da região de estudo (na divisa política com o estado de MT), Nova Xavantina a 800 km e Rondonópolis a 380 $\mathrm{km}$. Todas muito distantes, o que revela que a semelhança do BHC e SCC da 
BHRJ com essas localidades se dá pela combinação aleatória dos fatores de influência, não sendo possível explicar com exatidão as causas.

Observando numericamente as características do BHC e os dados de Souza et al. (2013) verifica-se que o volume anual de chuva de Rondonópolis e Aragarças supera o total médio precipitado na BHRJ, que é praticamente idêntico ao de Nova Xavantina. Já a evapotranspiração potencial na BHRJ supera as demais localidades citadas. Portanto, pode se inferir que há probabilidade de maior efeito da radiação, da insolação e do vento, este último com estreita relação com o relevo.

O fator em comum com entre a BHRJ e as localidades supracitadas é o Bioma Cerrado o que ajuda a explicar a semelhança observada. Especialmente a vegetação na BHRJ, o relevo e o solo são típicos dos cerrados brasileiros.

A precipitação média diária é de $3,7 \mathrm{~mm}$ irregularmente distribuída durante o ano, caracterizando uma região de estações úmidas e secas bem definidas.

Os dados da Figura 4 corroboram com a realidade da área de estudo, que apresenta dois períodos distintos: úmido (entre novembro e março) e seco (entre abril e outubro). Resultado também confirmado pela classificação de meses secos e úmidos conforme metodologia proposta por Thorntwaite (1948), cujos resultados são apresentados na Tabela 3, em que os valores de P-ETP/ETP positivos indicam meses úmidos e os negativos, meses secos.

Tabela 3 - Classificação de meses secos e úmidos, com base nos dados interpolados para o centro de gravidade da BHRJ.

\begin{tabular}{|c|c|c|c|c|c|c|c|c|c|c|c|c|}
\hline Classificação & & Úmidc & & & & & Secos & & & & Úm & \\
\hline Mês & Jan* & Fev* & Mar* & $A b r$ & Mai & Jun & Jul & Ago & Set & Out & Nov* & Dez* \\
\hline (P-ETP)/ETP & 0,43 & 0,73 & 0,45 & $-0,33$ & $-0,64$ & $-0,92$ & $-0,95$ & $-0,95$ & $-0,73$ & $-0,20$ & 0,23 & 0,58 \\
\hline P/ETP & 1,43 & 1,73 & 1,45 & 0,67 & 0,36 & 0,08 & 0,05 & 0,05 & 0,27 & 0,80 & 1,23 & 1,58 \\
\hline
\end{tabular}

*meses úmidos.

Observam-se com destaque os meses de julho e agosto como os mais secos e o mês de fevereiro como o mais úmido. O mês de novembro com valor próximo a zero $(0,23)$, indica que, embora seja um mês úmido, nesse período a precipitação infiltrada está contribuindo para reposição da umidade no perfil do solo, situação que perdura até janeiro, conforme Figura 4.

Avaliando os períodos (secos e úmidos) separadamente verificam-se, em média para a $B H R J$, valores de P/ETP igual 1,48 e 0,32 para o período úmido e seco, respectivamente. Esse resultado revela que no período úmido a precipitação é $48 \%$ maior do que a evapotranspiração e no período seco é apenas 32\% desta. Miranda e Santos (2008), em estudo realizado em Duas Barras/RJ, encontraram 1,90 para a estação chuvosa e 0,55 para a estação seca e Santana et al. (2004) citados pelos mesmos autores encontraram 0,38 para a estação seca no município de Serra Negra do Norte/CE. Por esses resultados observa-se que o período seco, na BHRJ, aproxima-se mais da região semiárida de Serra Negra do Norte/CE do que Duas Barras/RJ. Esse resultado ajuda a 
explicar as observações de campo dando conta de obras de infraestrutura típicas de regiões que convivem com situação de seca extrema, mesmo numa região onde a precipitação anual é elevada e que tem uma estação chuvosa típica com 3 meses de excedente hídrico.

Na Tabela 4 são apresentados dados de balanço hídrico de outros autores para a região circunvizinha a bacia do Jauquara, os quais servem de comparativo com os dados obtidos por interpolação para o centro de gravidade da BHRJ.

Tabela 4 - Dados obtidos confrontados com estudos de Ribeiro (2008) para Cáceres, Cuiabá e Diamantino.

\begin{tabular}{ccccccccccc}
\hline Estação & Série & $\begin{array}{c}\text { Prec. } \\
\text { anual } \\
\text { média } \\
(\mathbf{m m})\end{array}$ & \multicolumn{2}{c}{ Meses Críticos } & ETP & ETR & EXC & DEF & Método \\
\hline BHRJ & - & 1344,3 & Jun & Jul & Ago & 1476,2 & 1102,5 & 373,7 & 241,7 & BHC \\
Cáceres & $1961-$ & 1202,2 & Jun & Jul & Ago & 1612,7 & 1137,3 & 64,96 & 475,4 & BHC \\
& 2007 & & & & & & & & & \\
Cuiabá & $1961-$ & 1495,4 & Jun & Jul & Ago & 1728,3 & 1355,7 & 139,6 & 372,5 & BHC \\
& 2007 & & & & & & & & & \\
Diamantino & $1961-$ & 1793,5 & Jun & Jul & Ago & 1377,4 & 1459,7 & 333,8 & 268,6 & BHC \\
\hline
\end{tabular}

Em relação aos estudos para as estações meteorológicas mais próximas à BHRJ, as localidades apresentam precipitações médias anuais na faixa entre 1200 - 1900 mm e meses críticos entre junho e agosto, nos quais são registradas as menores médias pluviométricas anuais. Os maiores índices de evapotranspiração potencial constatados foram na estação de Cuiabá e Cáceres (1728 - $1612 \mathrm{~mm}$ ), indicando maior perda hídrica. As estações meteorológicas de Cuiabá (Lat $-15,55$ ) e Cáceres (Lat -16,05) possuem Latitudes semelhantes, o que sugere uma radiação global incidente também semelhante, portanto as maiores evapotranspirações potencias podem ser explicadas pela ocorrência de altas temperaturas e baixa capacidade de armazenamento de água no solo. Nota-se também (Tabela 4) que, embora a precipitação anual e a evapotranspiração potencial da BHRJ esteja numericamente no intervalo entre Cáceres e Cuiabá, o déficit hídrico é menor, contabilizando apenas 241,70 mm, contra 475,40 para Cáceres e 372,50 para Cuiabá. No entanto, o déficit hídrico em todas as localidades utilizadas nesta comparação se concentra nos meses de junho a agosto.

Referente ao planejamento agrícola, conhecer o comportamento hídrico é importante para o pleno desenvolvimento das culturas em termos de produtividade, rendimento e desenvolvimento, uma vez que possuem maior necessidade de água na fase de desenvolvimento inicial. O conhecimento das variações climáticas e do regime hídrico também oferece maior segurança aos investidores que podem prever a safra com maior acurácia. As variações climáticas refletem as expectativas de mudanças do clima de um local para outro ou do mesmo local ao longo do tempo. Neste estudo, a classificação climática reflete as características do microclima na BHRJ e permite 0 planejamento dos empreendimentos agropecuários e a gestão ambiental na Bacia. Já o regime hídrico é indicador da disponibilidade hídrica e de sua variação no ciclo hidrológico anual e é igualmente importante para gestão dos recursos hídricos e tomada de decisão de investimentos. 
Os meses críticos afetam também as populações que dependem da disponibilidade de água. Para tanto, medidas de captação das águas pluviais por cisternas e sistemas de captação (telhas, bombas, calhas, entre outros) e poços interligados são soluções alternativas, como mostrado por Alves (2016) em comunidade rural no município de Jangada- MT devido ao potencial de captação e armazenamento, como revelam os estudos de captação de águas pluviais por telhados e telhados verdes de Cassettari (2017) no município de Barra do Bugres-MT e Louzada et al. (2014) nos municípios de Vera e Rondonópolis- MT, estimando volumes médios mensais de 157,92, 37,29 e 101,70 m3, respectivamente.

\section{CONCLUSÕES}

Este trabalho avaliou o regime hídrico da BHRJ a partir da interpolação de dados climáticos de estações vizinhas, uma vez que não há estações climatológicas oficiais na bacia. A técnica de interpolação utilizada possibilitou estimar as variáveis climáticas para o Centro de Gravidade (CG) da bacia mediante as séries históricas obtidas das estações climatológicas oficias do Instituto Nacional de Meteorologia.

O CG foi escolhido como ponto geométrico mais representativo da bacia uma vez que não havia outra referência física ou política sugestiva. A instalação e operação de uma Estação Climatológica no CG (ou próximo dele) poderá no futuro validar os dados obtidos neste artigo.

Os dados obtidos mostraram que há semelhança no comportamento hídrico na BHRJ com as estações avaliadas em estudos semelhantes, evidenciando que os meses críticos são junho, julho e agosto. Mesmo que essas semelhanças existam os resultados encontrados são importantes, pois retratam o comportamento do regime hídrico e dá uma classificação mais detalhada do clima local.

O extrato do balanço hídrico climatológico para o CG da BHRJ revelou três períodos distintos, havendo excesso hídrico no primeiro, déficit no segundo e o terceiro período de reposições. O período de excesso hídrico coincide com a estação das chuvas, tipicamente nos meses de maior pluviosidade (Jan, Fer e Mar). Já o déficit hídrico ocorreu no período de estiagem contabilizando 7 meses nessa situação (Abr, Mai, Jun, Jul, Ago, Set, Out). Embora no mês de outubro já se constate chuvas na região, as vezes intensas, temperaturas e radiação solar elevadas associadas a uma baixa capacidade de armazenamento de água no solo contribuem para esse cenário de escassez em pleno cerrado brasileiro, na região Centro Oeste do Brasil, já na transição para o bioma Amazônico, numa das cabeceiras do Pantanal. O período de reposição do armazenamento de água no solo inicia-se em Novembro e vai até o início de Janeiro. As chuvas do mês de janeiro, como visto, complementa inicialmente o armazenamento de água do solo e feito isso o restante é convertido em excesso hídrico, o qual é convertido em percolação profunda (recarga dos aquíferos) ou escoamento superficial.

O tipo climático foi representado pela fórmula $C 2 w^{\prime}{ }^{\prime} b^{\prime} 4$, ou seja, clima Megatérmico com déficit hídrico moderado no inverno e evapotranspiração de $1476,2 \mathrm{~mm}$, ocorrendo $48 \%$ no verão. A classificação climática é um código que funciona com um registro geral para um determinado local. Por ele é possível compreender as características da região e até tomar decisões, além de ser 
possível estabelecer cenários comparativos com outros locais. A classificação climática obtida corrobora com a realidade da área de estudo (conforme BHC, observações de campo e relatos), que possui um período de deficiência hídrica no inverno e concentração da precipitação no verão.

Esse trabalho, inédito para a BHRJ, disponibiliza informação científica relevante e contribui para divulgação de uma importante região do estado de Mato Grosso a qual possui um extenso rebanho bovino de corte, produz cana de açúcar para geração de açúcar, álcool, levedura e energia, concentra diversas Comunidades Remanescentes de Quilombos e Assentados dos programas de reforma agrária, está na confrontação com uma Aldeia Indígena (UMUTINA), faz parte de um dos Festivais Nacionais de Pesca, possui grande potencial para o turismo ecológico e de aventura ainda pouco conhecido e explorado. Além disso, as formações rochosas da Província Serrana, que fazem parte da BHRJ, são ricas em Calcário que sustentam alguns empreendimentos que exploram esse minério com aplicação na construção civil e agricultura.

Ainda cabe ressaltar que o rio Jauquara é um dos afluentes da margem esquerda do alto rio Paraguai, portanto é uma das nascentes de cabeceira do Pantanal. O regime hídrico na BHRJ e a gestão dos recursos hídricos com foco no uso múltiplo e sustentável é fundamental para manutenção das águas que chegam à maior planície inundada do mundo, e este artigo vem para contribuir.

\section{AGRADECIMENTOS}

À Universidade do Estado de Mato Grosso (UNEMAT) por disponibilizar os recursos tangíveis necessários para realização do estudo.

Ao PIBIC/UNEMAT pela concessão da bolsa de iniciação científica (Edital 002/2016).

À Fundação de Amparo à Pesquisa do Estado de Mato Grosso (FAPEMAT) pela concessão de recursos financeiros para a pesquisa (Edital Universal No 005/2015, Processo No 221509/2015).

INMET pela disponibilização dos dados meteorológicos, sem os quais não seria possível a realização deste trabalho.

\section{REFERÊNCIAS}

ADAMI, M.; FREITAS, R. M. de; PADOVANI, C. R.; SHIMABURUKO, Y. E.; MOREIRA, M. A. Estudo da dinâmica espaço-temporal do bioma Pantanal por meio de imagens MODIS. Pesquisa agropecuária brasileira, Brasília, v.43, n.10, p.1371-1378, 2008.

ALVES, M. F.; MARCHETTO, M.; CURI, S.; PIMENTEL, G.; RODRIGUES, R. V. Avaliação de sistema de cisternas para captação de água de chuva instalados em comunidades rurais de Mato Grosso- Brasil. Engineering and Science, v.1 n.5. p.40-48, 2016.

APAYDIN, H.; SONMEZ, F. K. YILDIRIM, Y. E. Spatial interpolation techniques for climate data in the GAP region in Turkey. Climate Research. v.28, p.31-40, 2004. 
AQUINO, C. M. S.; OLIVEIRA, J. G. B. de. Emprego do método de Thornthwaite \& Mather (1955) para cálculo do balanço hídrico climatológico do núcleo de degradação de São Raimundo Nonato-Piauí. Revista Brasileira de Geografia Física, v.6, n.1, p.79-90, 2013.

AYOADE, J. O. Introdução a climatologia para os trópicos. 4 ed. Rio de Janeiro: Bertrand Brasil, 1996, 332 p.

BACCI, D. C.; PATACA, E. M. Educação para a água. Estudos Avançados, v.22, n.63, p.211-226, 2008.

BIER, A. A.; FERRAZ, S. E. T. Comparação de metodologias para preenchimento de falhas em dados meteorológicos para estações no sul do Brasil. Revista Brasileira de Meteorologia, v.32, n.2, p.215-226, 2017.

BURT, C. M. Irrigation water balance fundaments. Conference on Benchmarking Irrigation System Performance Using Water Measurement and Water Balances. USCID - San Louis Obispo, 1999.

CASARIN, R.; NEVES, S. M. A. S.; NEVES, R. J. Uso da terra e qualidade da água da bacia hidrográfica Paraguai/Jauquara-MT. Revista Geografia Acadêmica, v.2, n.1, p.33-42, 2008.

CASSETtARI, G. A.; QUEIROZ, T. M. de; MANVAILER, R. H. M. Potencial de captação de água de chuva por telhados no assentamento dos produtores rurais Antônio João e Maria, município de Barra do Bugres/MT. Revista IberoAmericana de Ciências Ambientais, v.8, n.2, p.325-334, 2017.

CASSETTARI, G. A.; QUEIROZ, T. M. Morphometric characterization of the hydrographic basin of Jauquara river in the transition between the Cerrado and Amazon biomes in Mato Grosso-Brazil. FLORESTA, v.49, n.2, p.325-334, 2019.

CECÍlio, R. A.; SILVA, K. R. da; XAVIER, A. C.; PEZZOPANE, J. R. M. Método para a espacialização dos elementos do balanço hídrico climatológico. Pesquisa Agropecuária. Brasília, v.47, n.4, p.478-488, abr. 2012.

DOURADO-NETO, D. VAN LIER, Q. J.; METSELAAR, K.; REICHARDT, K.; NIELSEN, D. R. General procedure to initialize the cyclic soil water balance by the Thornthwaite and Mather method. Scientia Agricola. Piracicaba, v. 67, n. 1, jan./fev. 2010.

FERREIRA, F. S. Qualidade da água nas bacias do Rio Sepotuba e Jauquara- MT, para uso doméstico e agrícola. 2015. 47 f. Dissertação (Mestrado em Ambiente e Sistemas de Produção Agrícola) - Universidade do Estado de Mato Grosso, Tangará da Serra, 2015.

FREITAS, G. M. de; PAPA, J. P.; AVILA, A. M. H de; PINTO, A. X. F. H. S. Estimativa de ocorrência de precipitação em áreas agrícolas utilizando floresta de caminhos ótimos. Revista Brasileira de Meteorologia, v. 25, n. 1, p.13-23, 2010.

FREITAS, J. C.; DANTAS, R. T.; ANDRANDE, A. R. S.; PEREIRA, E. R. R. Análise da variabilidade de índices climáticos para o Estado da Paraíba - PB. Revista Brasileira de Tecnologia Aplicada nas Ciências Agrárias, Guarapuava-PR, v.4, n.2, p.63-84, 2011.

GUTIÉRREZ, E. S.; DAVILA-VAZQUEZ, G.; SÁNCHEZ, J. A.; TORRES, J. J. D. 
Estimación del balance hídrico mediante variables climáticas, en la cuenca del río Cazones, Veracruz, México. Revista Ambiente e Água. Taubaté, v.8, n.3, sep./dec. 2013.

KURTZMAN, D.; KADMON, R. Mapping of temperature variables in Israel: a comparison of different interpolation methods. Climate Reseach. v.13, p.33-43, 1999.

LEMOS FILHO, L. C. A.; CARVAlHo, L. G.; EVANGELISTA, A. W. P.; ALVES JÚNIOR, J. Análise espacial da influência dos elementos meteorológicos sobre a evapotranspiração de referência em Minas Gerais. Revista Brasileira de Engenharia Agrícola e Ambiental, v.14, n.12, p.1294-1303, 2010.

LOUZADA, N. V.; QUEIROZ, T. M. de.; FAGUNDES, M. C.; SANCHES, J. C. M. Potencial de utilização do excesso hídrico para a irrigação de "tetos ecológicos" em duas zonas bioclimáticas no estado de Mato Grosso. Biosci. J., Uberlândia, v. 30, n.5, p.1389-1394, 2014.

MARACAHIPES, L.; LENZA, E.; MARIMON, B. S.; OLIVEIRA, E. A. de; PINTO, J. R. R.; MARIMON JUNIOR, B. H. Estrutura e composição florística da vegetação lenhosa em cerrado rupestre na transição Cerrado-Floresta Amazônica, Mato Grosso, Brasil. Biota Neutrop., v.11, n.1, p.133-142, 2011.

MATOS, R. M.; MEDEIROS, R. M.; FRANCISCO, P. R. M.; SILVA, P. F.; SANTOS, D. Caracterização e aptidão climática de culturas para o município de Alhandra PB, Brasil. Revista Brasileira de Agricultura Irrigada, v.9, n.3, p.183-192, 2015.

MEDEIROS, R. M.; SANTOS, D. C.; SOUSA, F. A. S.; FILHO, M. F. G. Análise climatológica, classificação climática e variabilidade do balanço hídrico climatológico na baciado Rio Uruçui Preto, PI. Revista Brasileira de Geografia Física, v.6, n.4, p.652-664, 2013.

MIRANDA, R. A. C.; SANTOS, A. S. Balanço hídrico e classificação climática de Thornthwaite em Duas Barras (RJ). Geo UERJ, Ano 10, v.1, n.18, 2008.

MOTA, L. L.; BOTON D.; FONSECA, R. C.; SILVA, W. C.; A. P. Souza. Balanço hídrico climatológico e classificação climática da região de Sinop, Mato Grosso. Scientific Electronic Archives, v.3, p.38-44, 2013.

NOBREGA, R. S. Um pensamento crítico sobre classificações climáticas: de Köppen até Strahler. Revista Brasileira de Geografia Física, v.3, n.1, p.18-22, 2010.

OLIVEIRA, M. R. P.; GALVANI, E. Avaliação do efeito orográfico na variação das precipitações no perfil longitudinal Paraty (RJ) e Campos do Jordão (SP). EntreLugar, Dourados, MS, v.6, n.11, p.133-151, 2015.

OMETTO, J. C. Bioclimatologia vegetal. São Paulo: Agronômica Ceres, 1981. $436 p$.

PARREIRA, A. G. B.; MARASCA, I. SOlinO, A. J. S.; SANTOS, G. O. Balanço hídrico climatológico para o município de Rio Verde, Goiás. Científic@ Multidisciplinary Journal, v.6, n.1, p.16-33, 2019.

PEREIRA, A. R. et al. Agrometeorologia: fundamentos e aplicações práticas. Guaíba: Agropecuária, 2002. 478 p. 
PESSOA, S. P. M.; GALVANIN, E. A. S.; NEVES, S. M. A. S. Mapping and use of forest occupation in the Paraguay River - Barra do Bugres / MT. Brazilian Journal of Cartography, v.6, n.66, p.1295-1303, 2014.

RADIN, B.; MATZENAUER, R. Uso das informações meteorológicas na agricultura do Rio Grande do Sul. Agrometeoros. v.24, n.1, p.41-54, out. 2016.

REBOITA, M. S.; GAN, M. A.; ROCHA, R. P.; AMBRIZZI, T. Regimes de precipitação na América do Sul: uma revisão bibliográfica. Revista Brasileira de Meteorologia, v.25, n.2, p.185-204, 2010.

ROSSATO, L.; AVALÁ, R. C. S.; TOMASSELA, J. Variação espaço-temporal da umidade do solo no Brasil: análise das condições médias para o período de 1971-1990. Revista Brasileira de Meteorologia, v.19, n.2, p.113-122, 2004.

RIBEIRO, H. W.; GALVANIN, E. A. S.; PAIVA, M. M. Análise das pressões antrópicas na bacia Paraguai/Jauquara-Mato Grosso. Ciência e Natura, Santa Maria v.39, n.2, p.378-389, 2017.

RIBEIRO, W. G. Aqüífero Guarani: gestão compartilhada e soberania. Estudos Avançados, v.22, n.67, p.227-238, 2008.

SILVA, A. O.; MOURA, G. B. A.; KLAR, A. E. Classificação climática de Thornthwaite e sua aplicabilidade agroclimatológica nos diferentes regimes de precipitação em Pernambuco. Irriga, Botucatu, v.19, n.1, p.46-60, janeiromarço, 2014.

SOBRINHO, T. A.; RODRIGUES, D. B. B.; OLIVEIRA, T. S. de., REBUCCI, L. C. S.; PERTNUSSSATI, C. A. Estimativa da evapotranspiração de referência através de redes neurais artificiais. Revista Brasileira de Meteorologia, v.26, n.2, p.197203, 2011.

SOUZA, A. P. de; MOTA, L. L.; ZAMADEI, T.; MARTIM C. C.; ALMEIDA, F. T. de; PAULINO, J. Caracterização climática e balanço hídrico climatológico no estado de Mato Grosso. Nativa, Sinop - MT, v.1, n.1, p.34-43, out./dez, 2013.

THORTHWAITE, C.W. An approach toward a rational classification of climate. Geographic Review, v.38, p.55-93, 1948.

THORNTHWAITE, C. W.; MATHER, J. R. The water balance: publications in climatology. New Jersey: Drexel Institute of Technology, 1955. $104 \mathrm{p}$

VALADÃO, R.M. As aves da Estação Ecológica Serra das Araras, Mato Grosso, Brasil. Biota Neotrópica, v.12, n.3, 2012.

ZHANG, Lu; WALKER, G. R.; DAWES, W. R. Water balance modelling: concepts and applications. Regional Water and Soil Assessment for Managing Sustainable Agriculture in China and Australia, n.84, p.31-47, 2002 